\title{
NOTES ON THE HAUNTS AND HABITS OF GLOSSINA TACHINOIDES, NEAR GEIDAM, BORNU PROVINCE, NORTHERN NIGERIA,
}

\section{By Dr. Bernard MoIser, W.A.M.S.}

The following notes are presented in the simple form in which they were jotted down at the time, as it seems to me that this will be the best way to give a clear idea of what was observed.

On 3rd Nov. 1911, I received native information as to the presence of tsetseflies at Bellaram, about $4 \frac{1}{2}$ miles S.W. of Geidam, North Bornu. I therefore sent out a man the next day to catch some of the flies and he returned the same evening with four specimens of Glossina tachinoides. On 6th Nov. I went to the place to investigate the haunts and habits of the flies.

The country generally is flat and sandy, with clay on the surface in parts, the subsoil being clay and white sand. The River $W$ obe runs a tortuous course in a broad valley about $1 \frac{1}{2}$ miles wide, with marshes on either side, which vary greatly in extent. In the drier portion of the valley there are shady trees in parts, with open spaces covered with long grass at this time of the year, while here and there occur patches of dense jungle, with thick undergrowth and twining creepers. It was in one of these thick patches of jungle that I found the flies to be located. The accompanying map (plane table) shows the position and surroundings of the "belt."

The "Bulama" (headman) of the village of Bellaram, about $1_{4}^{3}$ miles distant from the belt, says that the flies have existed in this spot ever since he was born (about 30 years). He says they are confined to the thick bush, and only occasionally leave it. He knows of the case of one man, a constant grower of onions in the "kurimi" (the patch of dense bush), and consequently much bitten by the tsetse-flies, who died after about a year's illness, during the last 8 or 9 months of which the man "did nothing but sleep." He was awakened for food, and then immediately went to sleep again. This history seems strongly suggestive of a case of sleeping sickness.

Also, two men, of about 60 years of age, from the same village, say that the flies have existed in the kurimi during the whole of their lifetimes, and that their fathers had told them that the flies have always been there. They say that the tsetses are more numerous in the kurimi in the dry weather, when there is little water in the river, from February to June. They explain this by saying that in the wet weather when the "fadama" (open marshy land) is covered with long rank grass the flies come out of the kurimi and enter the grass, where a few can sometimes be found. When dry, the grass is always burnt, and so, for want of cover, the flies retire to the kurimi.

On the map will be seen the village of Dama, on the opposite side of the valley, but only about 400 yards from the nearest point of the kurimi, and separated from it by open marsh and river. I interrogated the people of this village, and they told me that they know that the flies live in the kurimi, but that they never cross the river into their village. These people keep numbers of cattle there, so that it appears that the flies are very loth to cross the open ground. 
The birds seen were guinea-fowl, francolin, pigeons and doves, hornbills, night jars (?), finches, \&c.

7 th Nov.-I remained in the kurimi all day with eleven men. The flies bit us freely, except for a couple of hours in the middle of the day, when they were noticeably scarce. They were at all times very difficult to catch. We did not observe one on the ground, nor resting on tree-trunks or leaves. While sitting for several hours in one place, it was noticed that sometimes half-a-dozen flies suddenly appeared, remained to feed on us for say five minutes, then took to flight, and then for a space of ten minutes or so no flies would be seen, when again more would suddenly come on the scene. I had six men posted up trees, at heights varying from 10 to 25 feet, for an hour, and not one of them reported having seen a fly, although we on the ground saw several during that time. So it appears that the flies always keep fairly close to the ground.

The method of feeding was observed to be as follows :-

The fly alighted on the skin of a human being and remained quite still for 5 to 20 seconds with its proboscis enclosed in the palpi and held in a line with its body. Then the fly adjusted the position of its legs, so as to raise its body, the proboscis was suddenly brought down at right angles to the line of the body, perpendicular to the skin of the man, and at the same time the palpi were raised a little higher. The proboscis was then driven into the skin, steadily and continuously, almost up to the bulb. After remaining thus for 3 or 4 seconds, the proboscis was retracted without withdrawing the tip, and again driven in. Each act of insertion and retraction occupied about 8 to 12 seconds, the rate of insertion being much slower than that of retraction. These movements were repeated 5 or 6 times, as a rule, and at the end of that time the fly was distended with blood and took to flight.

The bite was generally attended by a pricking sensation, but sometimes there was no feeling whatever. Only one bite caused me considerable itching, which lasted into the next day. The flies settled most frequently on the bare backs of the men, who were sitting on the ground. They also bit me freely through the back of my dark brown "bush-shirt," as well as on my bare forearms and hands. I saw a few on the shaven heads of the men.

9th Nov.-Examined closely the edges of the marsh, but saw very few tsetse, and those seen were nearly always under the shade of large trees, very rarely in the open sunlight. In several specimens, both male and female, caught to-day, distended with blood, I noticed a large bubble of gas in the abdomen. The bubble remained uppermost when the fly was slowly rotated round a horizontal axis, and also ascended as far as the last segment but one, when the fly was held head downwards.

Spent some time trying to see tsetse-flies at rest on the ground, but did not see one in that position.

10th Nov.-Twenty-five flies were placed in one bottle (A), and four in another (B), and closely watched. The insects were very restless, rarely remaining stationary for more than a few seconds, and constantly rubbing together their fore and hind legs. When the flies are at rest, the distal third of the proboscis is often gently bent up and down, appearing above and below the palpi. They constantly stroke the head, abdomen, and wings with their legs, exactly 
after the manner of house-flies. When completely at rest, the halteres are motionless, but when the hind legs are moved or rubbed together, the halteres are moved up and down, slowly enough to be easily followed by the eye.

On one occasion a fly was seen to feed upon the abdomen of another. The biter was a female, the bitten fly a male, which had been on its back for some time, unable to rise, and so appeared in a weakly condition, but was not dead. The female inserted the proboscis into the abdomen on the ventral aspect, and worked it backwards and forwards, never quite withdrawing it, but again pushing it in in another direction. While this was in progress, a second fly appeared, and attempted to obtain a feed from the same male, but was apparently driven off by the female spreading out her wings and legs.

In the evening the flies were very hungry, constantly feeling the sides and bottom of the bottle with the unsheathed proboscis. A bit of fairly dry branch of a tamarind tree, and two leaves of the ebony tree were put into the bottle $(\mathbf{A})$. The flies rarely alighted on the leaves, and only a few settled on the twig. One was seen trying to insert its proboscis between the bark and wood of the twig, the head of the fly being in a tremulous condition, suggesting supreme effort.

While watching a female at rest on the floor of the bottle, I noticed a violent contraction of the abdomen, starting from the thorax, and immediately a white larva was extruded. The fly remained on the spot for a few minutes, and then flew away. The larva was quite white, the "tumid lips" being absolutely transparent, resembling bubbles of water, and in a very short time regular rhythmic contractions commenced, starting at the posterior end. The larva was fixed to the floor, and could not be displaced by shaking the bottle. At the end of about ten minutes, the larva was dry, but was still fixed by the tumid lips, the anterior end moving from side to side slightly. Shortly afterwards, it could be displaced by shaking the bottle, and passed into a condition of perfect quietude, exhibiting no movement whatever.

About 4.30 p.m., the fresh liver of a fowl, attached to a piece of string, was lowered into bottle (A). For half an hour the flies took no notice of it, although they seemed to be frantic in their efforts to obtain a feed on the floor of the bottle. Then one fly, and others afterwards, settled on the liver, waited for a minute or so, and then inserted the proboscis into the liver, driving it steadily in as far as the bulb, partially withdrawing it, and again driving it in, repeating the process as many as 50 times, but the abdomen did not become distended to the same extent as it does when the fly feeds on a human being. A large amount of effort seemed to be necessary in retracting the proboscis, the forelegs being pushed hard against the surface of the liver.

At 5 p.m., six flies were dead, and I saw several flies feeding on these dead ones, the ventral surface of the abdomen being chosen as the site for the insertion of the proboscis, the dead fly lying on its back.

Later in the evening, I saw a larva deposited on the twig in the bottle. The larva was born tail-first, i.e., the tumid lips preceding the head and being deposited on to the twig, the rest of the body remaining at right angles to it; but later the larva assumed a more vertical position. This larva never showed any movement, and $I$ am inclined to think that it was killed by the last segment coming into such close contact with the twig. About an hour later, I noticed that four lirvae had been deposited on the floor of the bottle. 
To-day, my boy informed me that he had seen one tsetse in the camp, about a mile from the belt. This fly must certainly have been a "follower."

The four flies put into the bottle (B) at 11 a.m., were given no food or water. One was a male, and was not distended with blood. This fly was dead at 5 p.m. The other three-females, distended with blood-were still alive and strong.

11th Nov.-This morning, the three flies in bottle (B) are still alive, thongh evidently weak and hungry. They were all dead at 3 p.m., i.e., after about 29 to 30 hours of starvation.

In bottle (A) one more larva had been deposited during the night, on the piece of liver. It was taken out and placed in another bottle, containing an inch or so of earth at the bottom, to await development.

Nine adult flies are dead, the rest active, and feeding on their dead companions continually. I saw one fly trying to feed on a larva, but the larva was always pushed to one side by the fly in its efforts, so that the proboscis struck the floor of the bottle, and did not pierce the larva. Up to the present, I have kept one fly alive without food for $2 \frac{1}{2}$ days in a bottle in which I placed some water, as well as dried leaves and earth.

The idea occurred to me yesterday to set up a large mosquito net, $8 \times 8 \times 8$ feet in the kurimi, thus enclosing a portion of the natural haunt of the flies, in order to find out where they usually rest. Accordingly, at 7 a.m., we proceeded to the kurimi, and set up the net at a chosen spot, so as to enclose the stump of an ebony tree, bearing a few small branches and leaves, and we also put in and arranged branches of other trees of different kinds.

One of my boys and I entered the net at about 10 a.m., taking with us a bottle holding eleven tsetses which had just been caught, and which were then liberated within the net. At first the flies flew in all directions, some five or six of them alighting on the sides of the net, the others being lost to view for a time, but after a few minutes search, we discovered them resting, in an inverted position, on the underside of small branches and twigs close to the ground. They were always on the under side of more or less horizontal branches, and only occasionally on vertical stems. The branches most favoured were those of about $\frac{1}{4}$ or $\frac{1}{5}$ inch in diameter, and sometimes quite small twigs, but never on leaves of any kind. They usually remained seated for a few minutes only, rarely longer than five, meanwhile constantly rubbing their fore and hind legs together, and then took to flight again. They were not disturbed by shaking the branches, even if this were done quite roughly. One fly was seen to alight on the ground, after having been disturbed from a branch, taking up a position under some dead twigs and leaves. Later, a few more flies were seen on dead twigs on the ground.

We also took into the net a dead monkey, a guinea-fowl and a small blue bird, all of which had just been shot, and these were placed in various positions on the branches; but we never saw a single fly biting them, or even sitting on them, though the flies bit the boy and myself several times. About an hour later, eleven more flies were liberated within the net. One was seen to sit for a few minutes within a hole in the tree-stump. We never saw a fly on the under side of leaves, though these were carefully watched; nor was any fly seen to settle on the bole of the tree, except the one that went into the hole, and this did not remain there long. 
We did not see a female deposit a larva within the net, though we noticed half a dozen pregnant females on the ground. The flies did not attempt to feed on the juices of the branches and twigs. No particular kind of branch was specially selected as a resting place, though, as a matter of fact, I never saw a fly on the branch of a tamarind tree. No flies alighted on any branch which was more than 5 feet from the ground, and very few settled above 4 feet. Branches between 6 inches and 2 feet from the ground were those most frequently occupied by the tsetses, and I soon found I had to lie on the ground in order to observe them closely. When flying about the interior of the net, the flies generally were about 2 to 4 feet above the ground, rarely higher. I saw only one fly alight on the roof of the net (about 7 feet above ground), but they several times rested on the sides of the net.

The insects did not seem to be nearly so timid and easily put to flight when on branches, as when about to bite a human being, and it was remarkable how violently the branches had to be shaken sometimes, in order to make the flies take to the wing.

These observations were carried on till about 5 p.m.

13th Nov.-Set up the net in a sunny spot close to the kurimi at 9 a.m. A boy and $I$ entered the net, taking with us a living monkey, and we liberated about 30 flies within the net. A dozen of these had been kept without food yesterday, and only about 6 of them were strong enough to fly, the others walked on the ground. The monkey at once saw, and ate or pulled to pieces those on the ground. Up till 4 p.m., the monkey had been bitten four times, but on each of these occasions it felt the prick of the proboscis, and making a grab at the spot, drove away the fly before the latter had had time to obtain a meal of blood. One bite was on the forehead, the other three on the abdomen and sides. One other fly alighted on the monkey, who immediately saw it and drove it away. Several times the monkey drove away flies which were evidently about to alight on his coat.

About 2 p.m., I left the boy to continue observations in the net, while I went into the kurimi with eight men, and we had no difficulty in observing several flies at rest on the under side of small branches, generally within a foot of the ground, and most frequently about 6 inches. The highest one seen was $4 \frac{1}{2}$ feet above the ground. We had to crawl and lie on the ground, in order to see the flies, which always took up positions as indicated. A few we saw on the vertical stems of young ebony trees, of not more than $\frac{3}{4}$ inch in diameter. We failed to observe any fly on the ground, but this was possibly due to the extreme difficulty of detecting them in this position. Also, no fly was seen on a leaf of any kind.

Later, the monkey was taken into the kurimi. A native and I remained for an hour, till dark, with the monkey, which was allowed to climb small trees for half an hour, and was afterwards kept sitting quietly on the ground, but we did not see a single tsetse alight on the monkey, although several settled on ourselves.

Later still, at about 7.30 p.m., when it was quite dark, we again entered the kurimi, and attempted to discover the whereabouts of the flies with the aid of an electric lamp. I took ten men with me, but we did not see a tsetse-fly in the space of an hour, nor were we bitten by them, nor did we even hear them on the wing, although we shook the bushes violently. I am inclined to think that we 
did not persevere long enough, and had we had a better means of illumination, I think we should have seen the flies asleep on the under side of twigs, or possibly on the ground. I cannot think that the flies had left the kurimi, as the men suggested, or had ascended to the tree-tops, for we had left them in their usual position at dusk.

The following conclusions may be drawn from the fore-going observations and experiments.

(1) Deep shade and proximity to water appear to be the chief factors determining the localisation of the flies.

(2) The natural resting place of $G$. tachinoides is on the lower side of twigs and branches of undergrowth, under the shade of large trees, at a height usually not greater than a foot from the ground.

(3) They are very restless, and do not usually remain long in one position.

(4) The flies do not usually travel higher than 4 or 5 feet from the ground, and probably never ascend as high as 10 feet.

(5) They probably do not feed on monkeys or birds, but on ground animals, e.g., warthog, duiker or bushbuck.

(6) The flies require a meal fairly frequently, and cannot withstand starvation (without water) for longer than 24 to 30 hours. In captivity, at any rate, they will feed on the dead bodies of other tsetse-flies. I am inclined to think, that they may feed naturally on other insects, ticks, grass-hoppers, etc. They certainly feed voraciously on human beings.

(7) I am of opinion, that, during the day, the flies are constantly moving about from place to place within the fly-belt, i.e., in deep shade, and only for short periods rest on the under side of twigs and small branches, and perhaps on the ground.

22nd Dec., 1911.-Left Geidam by barge, and proceeded down the River Wobe. Found a belt of $G$. tachinoides, about 4 miles from Greidam, on the north bank. The flies first appeared in the barge, and, on going to the bank, I found a few to be harbouring in the bushes and long grass on the river bank. There was a belt of thick bush about 150 yards back from the river, and I found numerous tsetses in this bush.

24th Dec., 1911.-Investigated the river bush towards Bultua, about 16 miles eastwards from Geidam. I found two separate localised patches of G. tachinoides, neither of them being on the river bank, but bordering on marshes some little distance from the stream.

29th Dec., 1911.-Examined the river bush, west of Jigaje, about 12 miles east of Geidam. I found a belt of $G$. tachinoides on the river bank, probably one of those previously marked by Dr. Pirie; but the natives of the town told me that tsetse have only inhabited this place for the last two years, and were never there previous to this. Again the belt was very localised; being restricted to the thick jungle, formed of shady tamarind trees, ebony trees, and thorns, with a fair amount of undergrowth. The flies were fairly numerous in this belt, but less so than in the others.

Ten living specimens were put into a dry bottle, containing a little of the soil of the locality, and ten others into another similar bottle, except that some water was added. All the flies in the dry bottle were dead at the end of 26 hours, 
whereas most of the flies in the wet bottle lived for three days, and the last fly lived till the morning of the 3rd Jan., i.e., four complete days, witiout any food whatever.

In connection with this, it is interesting to note that I was told by a native of Jigaje that tsetse-flies are in the habit of settling on the mud, when the river is low, and inserting the proboscis to obtain water. I saw this occur several times in the wet bottle, but did not observe anything of the kind on the river bank, which I watched carefully for some hours; there was, however, plenty of water in the river close by.

6th Jan., 1912.-River Wobe, near Abari, about 6 miles E. of Geidam. I crossed to the north bank of the river in the early morning, and spent the day in examining the bush for tsetse. I found four separate and distinct localities occupied by the flies, all being $G$. tachinoides. None of these belts were close to the river, but bordering on marshes about one-half to one mile north of the river. In each case the flies were congregated in patches of thick shady bush, with a considerable amount of undergrowth, and they were peculiarly confined to these small areas, the intervening open bush being free from them. The chief trees were tamarinds, ebony trees and thorns. The animals seen were warthog, monkeys, gazelle, bushbuck and reedbuck.

In every instance there was standing water in close proximity. I noted a few flies resting on the under side of small twigs and branches close to the ground. I did not observe coitus to take place, but some of the females caught were certainly pregnant. The soil was dark fissured clay, covered, in the dense patches of bush, with humus and débris of twigs and leaves. As usual, the flies did not follow us far into the bright sunlight.

\section{A clearing experiment with Glossina tachinoides.}

The following is an account of an experiment carried out in the fly-belt near Bellaram, referred to above (see Map), the object of the experiment being to see if the cutting down of all undergrowth in the kurimi would get rid of the flies.

The clearing of the undergrowth in the kurimi was commenced on 3rd Feb., 1912, starting from the west end, and working gradually eastwards. When about 200 yards had been cleared, and the undergrowth piled into heaps, it was left to become thoroughly dry till Feb. 19th, on which date the dried heaps were burnt, and the ground thoroughly swept, all dried leaves and twigs being thus removed. Meanwhile, on Feb. 15th and 16th, about 500 men were employed in cutting down the rest of the undergrowth throughout the kurimi, and these freshly-cut heaps were then allowed to become dry.

Observations made on Feb. 17th, 19th and 20th, showed that the mere cutting down of the undergrowth had made no material difference to the distribution of the flies. They were still found in the same localities as before, and they did not seem to have spread outside the kurimi.

Of $49 G$. tachinoides examined, 29 were males and 20 females; of the latter five were found to be pregnant. The larva was squeezed out of the abdomen in each case, and it was found that in two the tumid lips were already black, these being white in the other three cases. I failed to find any pupae in the soil or amongst the débris of leaves ; nor did I see any flies go to the river to drink water.

Twelve flies were dissected, and examined microscopically for the presence of flagellates, but none were found. 
On 17th Feb. two sheep were tied up in the kurimi for an hour, but no flies were seen to alight on them, though we were bitten several times. I saw some herds of cattle, sheep and goats grazing in close proximity to the kurimi, but failed to see a single tsetse on any of them. Several horses were tethered in the kurimi, and these were seen to be bitten by tsetses several times. I hope to be able to keep these horses under observation.

On 19th March I visited the place again, i.e., about a month after all undergrowth had been cut down, during which time the heaps had been allowed to lie on the ground to become dry.

From 10 a.m. till 3 p.m. I took observations in the belt. The cut undergrowth was still on the ground in large heaps, and now thoroughly dry. The remarkably small number of flies seen was in great contrast to the large numbers previously observed. In fact, only four specimens were caught by 14 men during that time, all four being males. It was very evident that the flies had left the kurimi, or were dead. Later in the day, several of the heaps of undergrowth were burnt.

20th March.-From 9 a.m. till noon, I made observations in the kurimi, and during that time I personally saw only two tsetse-flies. Twelve men were stationed in various parts of the kurimi, and they reported that they had only seen two flies, i.e., only four flies were seen altogether. Later, most of the remaining heaps of undergrowth were burnt. I spent many hours searching for pupa-cases, both in the loose earth, and amongst the débris in holes of trees, but without success.

On 2lst March, a search was made in the thick bush to the E. and S.E. of the kurimi, to ascertain where the flies had gone. Up to 2 p.m., twelve flies had been caught, six males and six females, of which two were pregnant. One of these extruded the larva after capture, the tumid lips being white.

Five of these flies were caught under a dense mass of shady trees and creepers surrounding a small pond. Unfortunately this particular spot had not been previously examined, so that it is impossible to say if the flies had existed there formerly or not. The other seven flies were caught at the spot marked by three red dots on the map, where we had seen tsetses formerly, so that I do not think these flies had come from the kurimi.

In the afternoon a couple of hours were spent in the kurimi, but only one fly was seen during that time. It is thus clear that the flies are no longer living in their former abode. The destruction of the undergrowth has resulted either in the desertion or death of these insects, and it would appear, as far as can be judged at present, that the flies have died, since they cannot be found anywhere in the neighbourhood. This seems to show that the presence of undergrowth (as well as shady trees) is a necessary condition in the habitation of G.tachinoides.

The next day, a few odd heaps of undergrowth, which had escaped destruction, were set on fire, so that now the kurimi is absolutely clear of undergrowth, but the tall shady tamarind and ebony trees are still standing. Dried leaves, etc., were also swept into heaps and burnt. During the whole of the day not a single tsetse-fly was seen in the kurimi.

Geidam, 23rd March, 1912. 

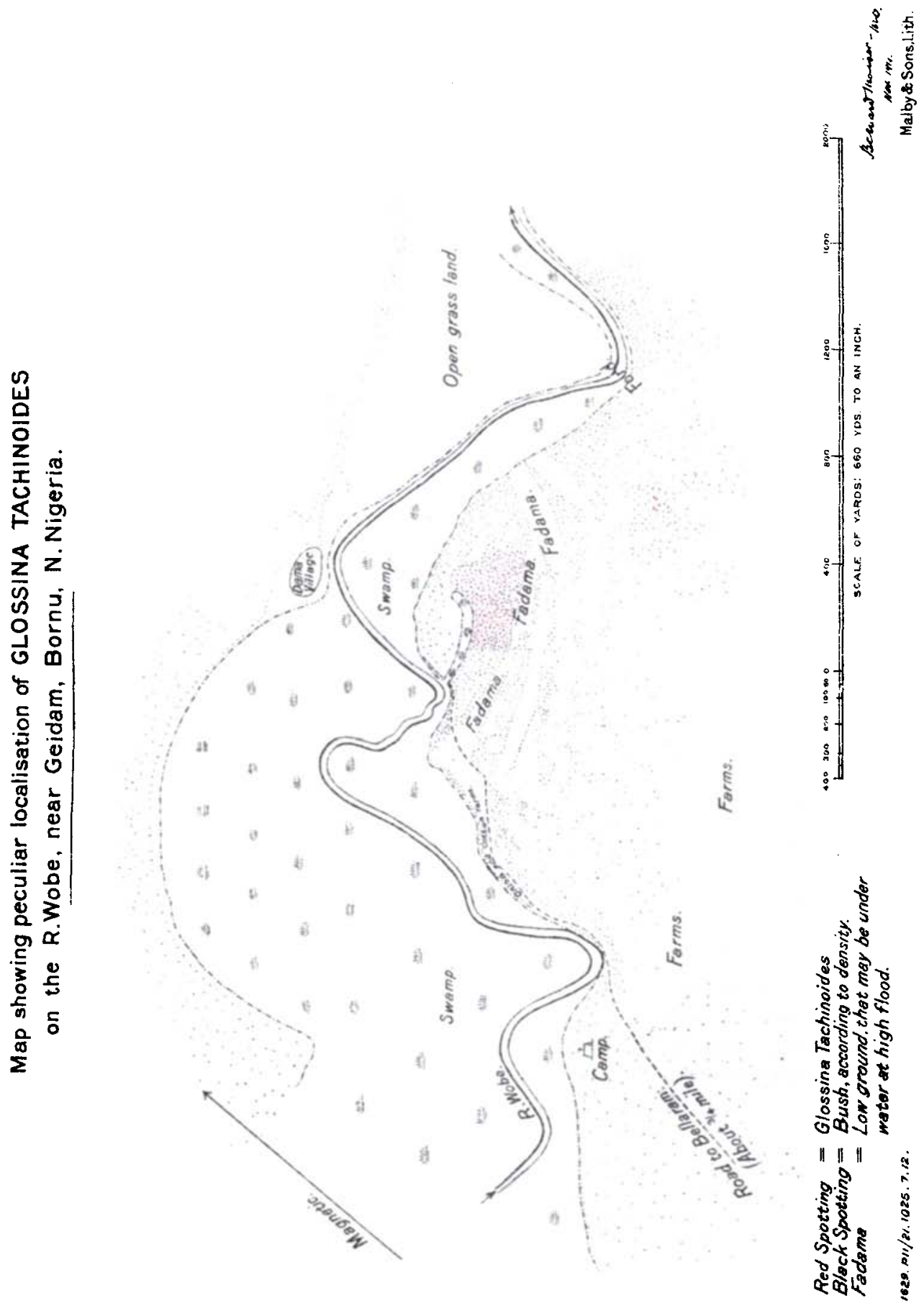